\title{
APLIKASI 3D VIRTUAL REALITY SEBAGAI MEDIA PENGENALAN KAMPUS POLITEKNIK NEGERI INDRAMAYU BERBASIS MOBILE
}

\author{
Firman Setiawan Riyadi ${ }^{1)}$, A.Sumarudin ${ }^{2)}$, dan Munengsih Sari Bunga ${ }^{3)}$ \\ 1,2,3) Teknik Informatika, Politeknik Negeri Indramayu \\ J1.Raya Lohbener Lama No.8 Lohbener Indramayu Jawa Barat 45252 Indonesia \\ e-mail: firmansetiawanr15@gmail.com ${ }^{1)}$, shumaru@polindra.ac.id ${ }^{2)}$, nengslim85@gmail.com ${ }^{3)}$
}

\begin{abstract}
ABSTRAK
Promosi dan pengenalan kampus yang dilakukan oleh beberapa Institusi pada umumnya masih menggunakan media gambar atau media cetak, sama halnya yang sering dilakukan oleh Politeknik Negeri Indramayu dalam mengenalkan dan memberikan informasi kampus yaitu masih menggunakan media cetak dan gambar seperti brosur atau spanduk. Oleh karena itu, diperlukan sebuah aplikasi yang bisa mengenalkan dan memberikan informasi seputar kampus khususnya di Politeknik Negeri Indramayu dan memberikan informasi gedung-gedung yang ada di kampus menggunakan teknologi Virtual Reality. Dengan adanya teknologi Virtual Reality mampu memberikan informasi secara nyata dan bisa berinteraksi langsung dengan lingkungan dan gedung yang ada di kampus walaupun pada tampilan gedung dan lingkungan masih terlihat low poly. Dengan menyiapkan smartphone yang sudah mendukung atau sudah support sensor Gyroscope dan menyiapkan kacamata Google CardBoard atau VRBox, pengguna bisa langsung menggunakan aplikasi $3 D$ virtual reality dan bisa langsung memainkannya, tetapi efek dari penggunaan aplikasi ini dapat menyebabkan pengguna sedikit terasa pusing karena tidak terbiasa menggunakannya. Aplikasi $3 D$ Virtual Reality ini dibuat dengan menggunakan software Unity, Blender, dan bahasa pemrograman C\#. Fitur yang tersedia dalam aplikasi ini adalah mulai VR, pilih gedung, cara pakai VR, dan tentang VR. Aplikasi 3D virtual reality dapat digunakan oleh Politeknik Negeri Indramayu sebagai media pengenalan Kampus berbasis mobile yang memiliki tampilan responsive yang bisa dijalankan di smatrphone yang sudah mendukung sensor Accelerometer. sensor Gyroscope, dan bersistem operasi Android.
\end{abstract}

Kata Kunci: aplikasi, Virtual Reality, sensor gyroscope, google cardboard, smartphone

\begin{abstract}
Campus promotion and introduction by some institutions in general still using the media images or print media, as is often done by State Polytechnic Indramayu in introducing and providing campus information is still using print media and images such as brochures or banners. Therefore, an application is required that can introduce and provide information about the campus, especially in the State Polytechnic Indramayu and provide information on existing buildings on campus using Virtual Reality technology. With the Virtual Reality technology is able to provide real information and can interact directly with the environment and buildings that exist in the campus although the appearance of the building and the environment still looks low poly. By setting up a smartphone that already supports or already support the Gyroscope sensor and set up Google CardBoard or VRBox glasses, users can directly use 3D virtual reality applications and can directly play it, but the effect of using this application can cause the user a bit dizzy because not used to using it. 3D Virtual Reality application is created by using software Unity, Blender, and C \# programming language. The features available in this app are VR start, select building, how to use VR, and about VR. 3D virtual reality applications can be used by the State Polytechnic Indramayu as a medium of introduction Mobile-based campus that has a responsive display that can be run on smatrphone that already supports Accelerometer sensor. Gyroscope sensor, and Android operating system.
\end{abstract}

Keywords: applications, google cardboard, gyroscope sensor, smartphone, Virtual Reality

\section{Pendahuluan}

$\mathrm{P}$ ada perkembangan teknologi yang sudah modern ini hampir semua operasional sudah didukung dengan aplikasi berbasis teknologi. Hal ini dikarenakan perkembangan teknologi yang semakin hari semakin pesat, sehingga memunculkan banyak inovasi-inovasi baru dari teknologi. Salah satu inovasi yang terbaru saat ini yaitu Virtual Reality. Virtual Reality merupakan teknologi yang telah membuat perbedaan besar pada sejarah pemikiran manusia dan saat ini sedang menjadi trend untuk membantu meningkatkan kualitas kinerja dan produk. Virtual Reality terdiri dari dua kata yaitu virtual dan reality yang berarti maya dan realitas. Virtual reality adalah teknologi yang dapat berinteraksi dengan suatu lingkungan yang disimulasikan oleh komputer. Secara teknisnya, virtual reality digunakan untuk menggambarkan lingkungan tiga dimensi yang dihasilkan oleh komputer dan dapat berinteraksi dengan seseorang. Contoh teknologi virtual reality yang cukup sederhana adalah Google Cardboard karena dibuat menggunakan kertas. Google Cardboard ini belum begitu mempunyai banyak fungsi, tetapi dengan 
menggunakan Google Cardboard pengguna akan merasakan pengalaman virtual reality dengan cara menggabungkan smartphone yang memiliki sensor gyroscope dengan Google Cardboard. Teknologi virtual reality ini biasanya digunakan pada bidang medis, properti, arsitektur, penerbangan, hiburan, dan lain-lain. Contoh virtual reality banyak sekali, salah satunya seperti game FPS (First Peson Shooter) yang akan membuat pengguna merasa berada di dalam game tersebut. Selain itu, virtual reality digunakan pada foto dan video 360 derajat yang membuat pengguna merasa berada di tempat tersebut [1].

Politeknik Negeri Indramayu sendiri masih menggunakan brosur atau spanduk sebagai media pengenalan kampus, dan hal tersebut dianggap sudah cukup. Akan tetapi media tersebut pada umumnya sudah banyak digunakan oleh instansi Sekolah, Perguruan Tinggi dan Universitas untuk melakukan pengenalan kampus sehingga dengan menggunakan media yang berbeda dengan yang lain dalam melakukan pengenalan kampus, yaitu dengan menggunakan teknologi Virtual Reality, dengan tujuan agar media promosi lebih menarik dari media sebelumnya dimana para pengguna dan calon mahasiswa dapat mengetahui dan mengenal informasi tentang lingkungan kampus melalui aplikasi dengan menggunakan objek tiga dimensi (3D).

Dengan adanya aplikasi Virtual Reality diharapkan pengguna dan calon mahasiswa baru dapat menggunakan aplikasi ini sebagai media untuk mencari informasi seputar kampus Politeknik Negeri Indramayu dengan cara tidak langsung ataupun langsung saat mengunjungi kampus tersebut.

\section{METODE}

\section{A. Virtual Reality}

Teknologi virtual reality yang lebih awal adalah Peta Bioskop Aspen, yang diciptakan oleh MIT pada tahun 1977. Programnya adalah suatu simulasi kasar tentang kota Aspen di Colorado, dimana para pemakai bisa mengembara dalam salah satu dari tiga gaya yaitu musim panas, musim dingin, dan poligon. Dua hal pertama tersebut telah didasarkan pada foto, karena para peneliti benar-benar memotret tiap-tiap pergerakan yang mungkin melalui pandangan jalan kota besar pada kedua musim tersebut, dan yang ketiga adalah suatu model dasar tiga dimensi (3D) kota besar. Akhir tahun 1980 istilah "Virtual Reality" telah dipopulerkan oleh Jaron Lanier, salah satu pelopor modern dari bidang tersebut. Lanier yang telah mendirikan perusahaan VPL Riset pada tahun 1985, telah mengembangkan dan membangun sistem "kacamata hitam dan sarung tangan" yang terkenal pada masa itu. Virtual Reality merupakan teknologi yang memungkinkan seseorang melakukan suatu simulasi terhadap suatu objek nyata dengan menggunakan komputer yang mampu membangkitkan suasana tiga dimensi (3D) sehingga membuat pengguna seolah-olah terlibat secara fisik.

Sistem seperti ini biasanya dapat digunakan untuk perancang obat, arsitek, insinyur, pekerja medis, dan bahkan orang awam untuk melakukan aktivitas-aktivitas yang meniru dunia nyata. Lingkungan virtual reality pada umumnya menyajikan pengalaman visual, yang ditampilkan pada sebuah layar komputer atau melalui sebuah penampil stereokopik, tapi beberapa simulasi mengikut sertakan tambahan informasi hasil pengindraan, seperti suara melalui speaker atau headphone. Contoh aplikasi virtual reality yang digunakan saat ini yaitu dalam bidang militer. Virtual reality dipakai untuk melakukan simulasi latihan perang, simulasi latihan terjun payung, dan sebagainya. Dimana dengan pemakaian teknologi ini bisa lebih menghemat biaya dan waktu dibandingkan dengan cara konvensional. Virtual reality sendiri memiliki efek negatif yaitu Cybersickness. Cybersickness adalah gangguan yang sering dialami dalam penggunaan virtual reality. pengguna akan merasa ketegangan mata dan bahkan disertai rasa pusing. Tekadang pengguna secara psikologis masih terbawa pada suasana semu walaupun sebenarnya pengguna sudah kembali ke dunia nyata. Jadi, gangguan ini tidak boleh dianggap remeh karena pengguna biasanya susah kembali ke dunia nyata dan selalu terangan-angan dalam dunia semu [2].

\section{B. Google CardBoard}

Google Cardboard merupakan wahana virtual reality yang dikembangkan oleh Google dengan menggunakan bahan karton yang dilipat dan menggunakan smartphone sebagai layarnya. Contoh penggunaannya adalah untuk bermain game virtual reality, menonton video dalam bentuk 3D, menonton film atau movie $360^{\circ}$ seperti yang umunya bisa lihat di facebook dan lain sebagainya. Sementara itu, teknologi yang menggunakan Google Cardboard adalah virtual reality atau kita kenal dengan istilah VR. Saat ini ada banyak sekali pengaplikasian dari Virtual Reality, seperti Game, Movie, dan sebagainya. Google Cardboard membuat anda dapat melihat objek dalam bentuk tiga dimensi (3D), dan seperti kenyataan. Hal ini adalah sisi menarik dari Google Cardboard [3].

\section{Unity $3 D$ Engine}

Game Engine seperti Unity adalah alat penggerak dibalik permainan - permainan (games) yang penulis ketahui dan gemari. Unity adalah salah satu alat pengembangan yang banyak digunakan dan digemari untuk pengembangan game dan digunakan oleh semua orang mulai dari penghobi hingga studio-studio besar untuk mengembangkan 
permainan - permainan (games) serta memberikan pengalaman interaktif dalam web, dekstop, ponsel, dan konsol [4].

\section{Blender $3 D$}

Blender adalah software modelling, rendering dan animasi tiga dimensi 3D yang kini menjadi primadona animator Indonesia dan seluruh dunia. Ukuannya yang (50 MB), kecepatan, kemudahan dan kelengkapannya bisa mengalahkan seniornya 3D Max dan Autodesk Maya. Selain modeling dan animasi 3D Blender juga bisa untuk video editing, video effects, image retouching, game development [5].

\section{HASIL}

\section{A. Pengumpulan data}

Dalam tahap ini terdapat pengumpulan data yang berupa gambar denah kampus Politeknik Negeri Indramayu, gambar bangunan gedung-gedung dan lingkungan tersebut untuk kemudian digunakan sebagai referensi pada proses pembuatan $3 D$ Modelling.

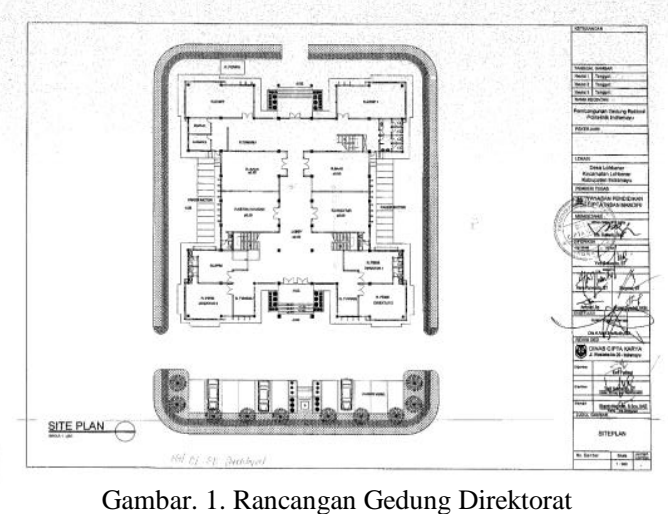

\section{B. Perancangan aplikasi}

Perancangan aplikasi yang dibangun berbasis Android. Dalam penerapannya akan dibuat sebuah objek 3D yang akan menampilkan gedung-gedung dan lingkungan yang ada di Kampus Politeknik Negeri Indramayu, kemudian setelah objek 3D sudah dibuat pengguna akan membutuhkan perangkat tambahan yaitu kacamata VR Google CardBoard untuk membantu pengguna agar bisa masuk dan berinteraksi secara langsung dalam dunia 3D. Berikut tahapan perancangan aplikasi virtual reality yang dapat dilihat pada gambar 2 .

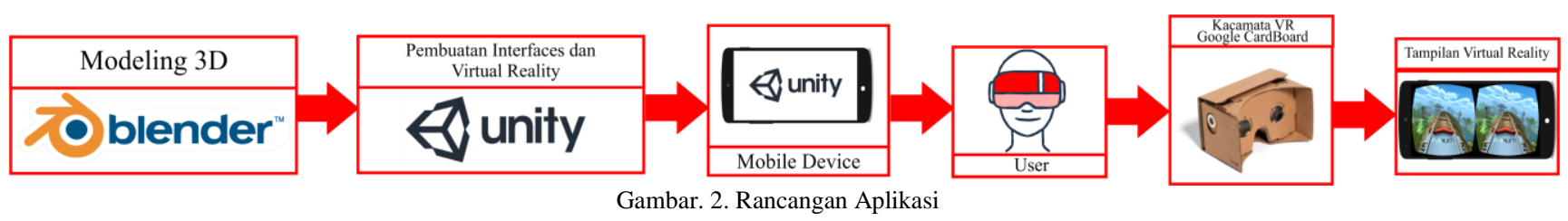

\section{Use Case Diagram}

Use Case Diagram adalah gambaran graphical dari beberapa atau semua actor, use case dan interaksi diantara komponen-komponen tersebut yang memperkenalkan suatu sistem yang akan dibangun, digunakan untuk menjelaskan bagaimana langkah - langkah yang seharusnya dikerjakan oleh sistem. Berikut ini adalah use case diagram dari aplikasi virtual reality berbasis mobile pada Kampus Politeknik Negeri Indramayu, untuk lebih jelasnya bisa lihat pada gambar 3 .

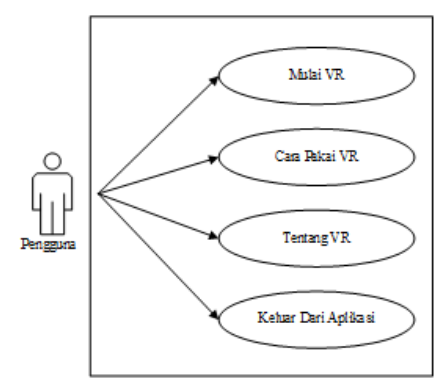

Gambar. 3. Use Case Diagram 


\section{Activity Diagram Mulai VR}

Menampilkan proses mulai atau menjalankan virtual reality. Adapun rancangan activity diagram ini dapat dilihat pada gambar 4.

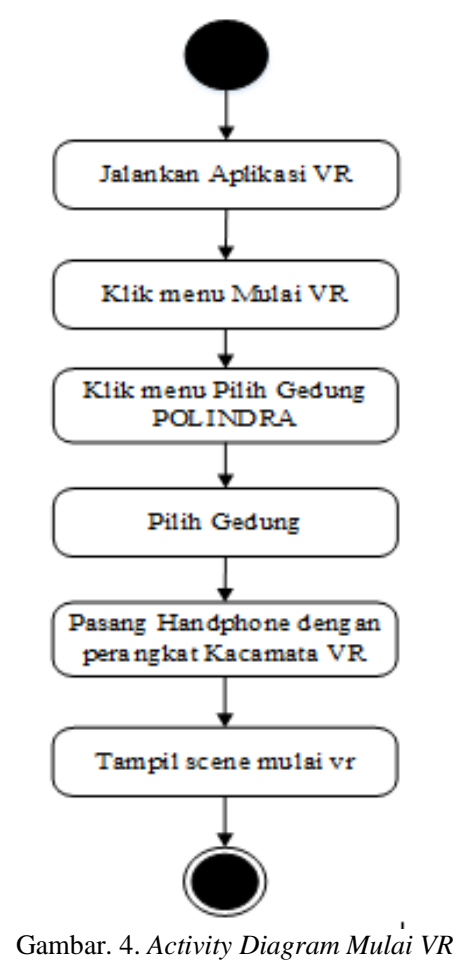

Aplikasi 3D Virtual Reality memiliki beberapa activity seperti terlihat pada Gambar 4, yang terdiri dari Jalankan Aplikasi VR dimana Pengguna menjalankan aplikasi VR untuk memulai aplikasi. Pilih menu Mulai VR maka Pengguna memilih menu mulai VR pada main menu. Setelah pengguna memilih menu mulai VR akan muncul menu pilih gedung polindra dengan pilihan berbeda pada setiap gedungnya. Dengan menekan tombol Pilih Gedung maka Pengguna memilih gedung yang ada di kampus. Kemudian Pasang Handphone dengan perangkat Kacamata VR, karena setelah pengguna memilih gedung yang ada di POLINDRA maka pengguna diminta untuk memasangkan handphone dengan kacamata VR. Setelah itu Tampil scene mulai VR dimana Pengguna bisa langsung berinteraksi dengan gedung dan halaman yang ada di POLINDRA.

\section{E. Sequence Diagram Interaksi}

Pada proses sequence diagram ini untuk menampilkan interaksi bisa dilihat pada gambar 5 .

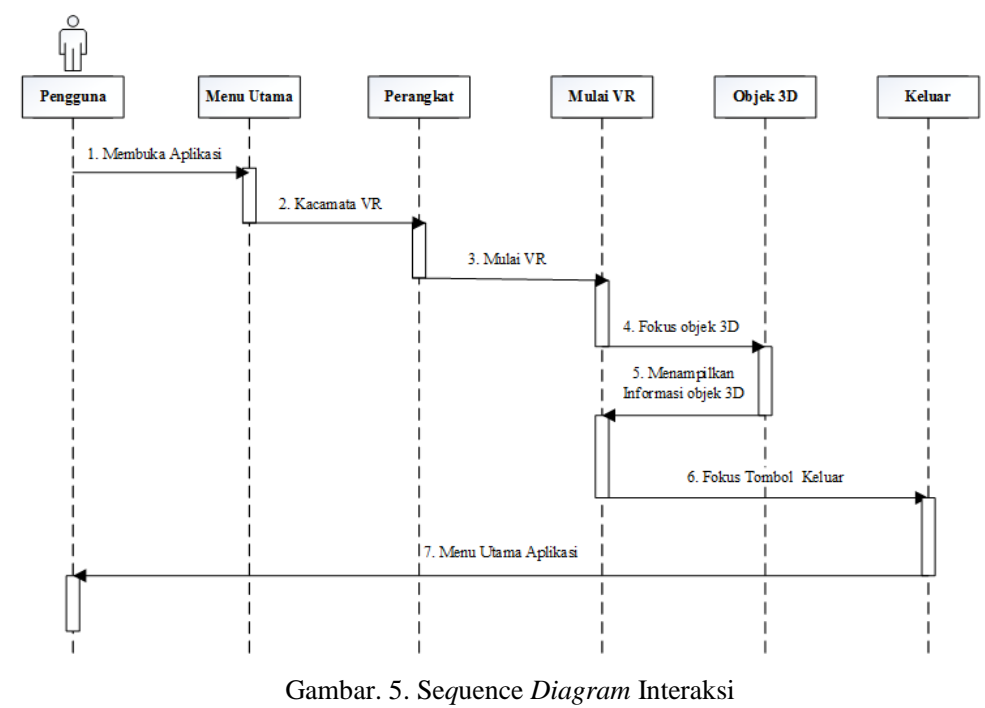

Berdasarkan gambar 5, pengguna menjalankan aplikasi VR untuk memulai aplikasi. Maka aplikasi akan menampilkan menu utama dan pengguna memilih menu aplikasi VR dan menyediakan perangkat kacamata VR. 
Kemudian pengguna mulai VR dan dapat berinteraksi dengan aplikasi VR POLIDRA. Di dalam aplikasi akan menampilkan Objek 3D yang menampilkan gedung POLINDRA. Jika fokus terhadap objek 3D maka akan muncul informasi gedung (objek 3D). Jika selesai, maka pengguna memilih menu Keluar untuk keluar aplikasi.

\section{F. Perancangan Interaksi Virtual Reality}

Pada perancangan interaksi akan menjelaskan bagaimana pengguna menggunakan aplikasi virtual reality dan bisa berinteraksi langsung dengan aplikasi virtual reality, dan interaksi yang penulis rancang akan dijelaskan di bawah ini.

1. Melihat dan Berjalan (Look Walk)

Pada aplikasi virtual reality ini menggunakan interaksi melihat dan berjalan (look walk), dimana pengguna bebas berinteraksi langsung dalam dunia 3D, dengan cara pengguna menggerakan kepalanya kebawah, kekanan dan kekiri maka secara otomatis sistem akan berjalan dan mengikuti intruksi dari pengguna. Setelah itu jika pengguna ingin berhenti dan melihat sekeliling dunia 3D, pengguna cukup menggerakan kepalanya menjadi lurus secara otomatis sistem akan berhenti berjalan dan bisa langsung melihat disekeliling dunia 3D dengan bebas.

2. Menampilkan Informasi

Pada interaksi ini akan menampilkan informasi nama - nama ruangan yang ada disetiap gedung. Dan bagaimana pengguna bisa melihat informasi tersebut, nanti setiap didepan gedung akan terdapat sebuah tanda yang akan memunculkan informasi dari gedung tersebut. Dan caranya pengguna hanya memfokuskan pandangannya ke tanda tersebut, maka secara otomatis akan muncul sebuah informasi, dan jika ingin menghilangkan informasi tersebut pengguna cukup memindahkan pandanganya ke arah yang bebas.

3. Exit

Pada interaksi ini dalam dunia 3D akan terdapat tombol exit yang berfungsi untu kembali ke menu utama aplikasi jika pengguna ingin keluar dari dunia 3D. Dengan cara pengguna hanya memfokuskan ke tombol exit dan tunggu sampai loading penuh akan secara otomatis akan kembali ke menu utama, tetapi jika loading tombol exit belum penuh pengguna tidak bisa kembali ke menu utama.

\section{G. Perancangan Interface}

Ada beberapa rancangan dari aplikasi virtual reality berbasis mobile yang akan dirancang. Untuk lebih jelasnya bisa dilihat pada Gambar 6.

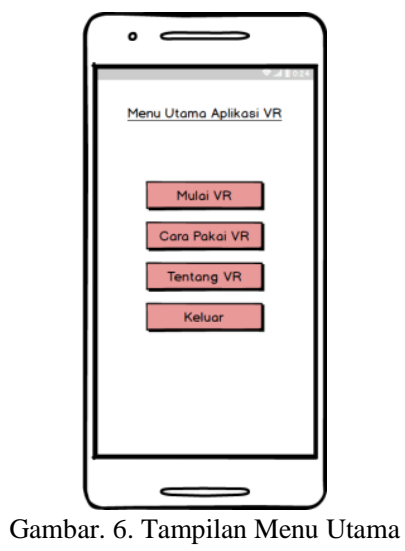

Perancangan interface aplikasi VR berbasis mobile terdapat 4 tombol sebagai menu utama yaitu mulai VR, cara Pakai VR, tentang VR dan Keluar. Ketika pengguna aplikasi menekan tombol Mulai VR maka akan masuk ke menu Pilih Gedung yang berisi pilihan menu seperti Semua Gedung Polindra, gedung Direktorat, Gedung Teknik Informatika, Gedung Bengkel Teknik Mesin, dan Gedung Bengkel Teknik Pendingin. Tombol cara pakai VR pada gambar 6 digunakan oleh pengguna untuk mengetahui cara penggunaan aplikasi yang berisi langkah-langkah penggunaan aplikasi, sedangkan tombol tentang VR berisi informasi tentang aplikasi dan jika pengguna ingin menghentikan aplikasi maka pilih tombol Keluar pada halaman menu utama aplikasi.

\section{PEMBAHASAN}

\section{A. Implementasi Pengujian Aplikasi}

Pada tahap ini setidaknya dibuat objek 3D karena pada aplikasi virtual reality ini seluruh aset atau objek yang dibuat berbentuk tiga dimensi (3D). Contoh tahapan-tahapanya sebagai berikut.

1. Implementasi Objek 3D 
2. Implementasi Pemodelan Objek 3D

3. Implementasi Pembuatan Virtual Reality

4. Debugging Aplikasi Virtual Reality

5. Implementasi Aplikasi Virtual Reality

\section{B. Implementasi Tampilan Aplikasi Virtual Reality}

1. Halaman Menu Utama

Setelah aplikasi dijalankan, dan langkah pertama adalah menampilkan halaman Menu Utama. Terdapat beberapa konten yang dapat diakses oleh pengguna yang dapat dilihat pada gambar 6 .

2. Halaman Menu Pilih Gedung POLINDRA

Pada halaman ini terdapat pilihan menu gedung yang nantinya akan menampilkan beberapa gedung tiga dimensi yang ada di POLINDRA yang terlihat pada gambar 7 .

3. Halaman Menu Cara Pakai VR

Pada halaman ini digunakan untuk memberikan langkah-langkah informasi tentang cara pakai menggunakan aplikasi virtual reality kepada pengguna, agar pada saat pengguna menggunakan aplikasi bisa langsung mengetahui cara pemakaiannya dan menggunakan aplikasinya dan langkah pertama yaitu menginstal aplikasi terlebih dahulu.

4. Halaman Menu Tentang VR

Pada halaman ini digunakan untuk memberikan pengetahuan tentang teknologi virtual reality kepada pengguna yang masih belum mengetahui apa itu teknologi virtual reality, dan pada halaman ini sedikit kesimpulan untuk memberikan apa itu teknologi virtual reality kepada pengguna.

5. Halaman Virtual Reality

Pada halaman ini terdapat tombol exit untuk keluar dari dunia 3D dan pada halaman ini juga terdapat menu informasi tentang gedung dan ruangan tertentu, dan ketika pengguna menekan menu pilih gedung POLINDRA maka akan muncul tampilan seperti yang terlihat pada gambar 7.

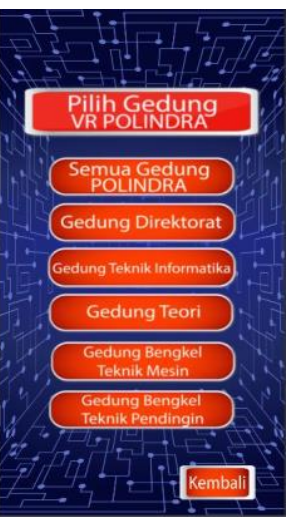

Gambar. 7. Halaman Pilih Menu Gedung POLINDRA

\section{Pengujian Pada Layar Smartphone}

Pada pengujian tersebut untuk mengetahui pada layar smartphone apa saja yang jika menginstal aplikasi ini bisa responsive saat dijalankan oleh pengguna. Berikut hasil pengujian pada layar smartphone yang dapat dilihat pada tabel I.

Tabel I

PENGUJIAN PADA LAYAR SMARTPHONE

\begin{tabular}{l|l}
\hline \multicolumn{1}{c}{ Resolusi } & Status \\
\hline HVGA Potrait $(320 \times 480)$ & Berhasil \\
\hline WVGA Potrait $(480 \times 800)$ & Berhasil \\
\hline FWVGA Potrait $(480 \times 854)$ & Berhasil \\
\hline WSVGA Potrait $(600 \times 1024)$ & Berhasil \\
\hline WXGA Potrait $(800 \times 1280)$ & Berhasil \\
\hline Potrait $(720 \times 1280)$ & Berhasil \\
\hline Potrait $(1080 \times 1920)$ & Berhasil \\
\hline 3:2 Potrait & Berhasil \\
\hline 10:16 Potrait & Berhasil \\
\hline \hline
\end{tabular}




\section{Pengujian Sistem Menggunakan Black Box}

Pengujian aplikasi ini menggunakan metode black box testing. Black box testing adalah pengujian yang dilakukan hanya mengamati hasil eksekusi melalui data uji dan memeriksa fungsional dari perangkat lunak. Jadi dianalogikan seperti penulis melihat suatu kotak hitam, penulis hanya bisa melihat penampilan luarnya saja, tanpa mengetahui ada apa dibalik bungkus hitamnya yaitu mengevaluasi hanya dari tampilan luarnya (interface) dan fungsionalitasnya saja tanpa mengetahui apa sesungguhnya yang terjadi dalam proses detailnya (hanya mengetahui input dan output). Pengujian dan hasil pengujian dapat dilihat pada tabel II, dan kesimpulan pengujian menyatakan bahwa semua fungsi berjalan dengan baik dan sesuai dengan yang diharapkan.

TABEL II

PENGUJIAN SISTEM MENGGUNAKAN BLACK BOX

\begin{tabular}{|c|c|c|c|c|c|}
\hline No. & Skenario Pengujian & Test Case & Hasil Yang di Harapkan & Hasil Pengujian & Kesimpulan \\
\hline \multicolumn{6}{|c|}{ Pengguna } \\
\hline 1 & $\begin{array}{l}\text { Menjalankan Aplikasi 3D } \\
\text { Virtual Reality Sebagai } \\
\text { Media Pengenalan Kampus } \\
\text { Politeknik } \\
\text { Indramayu Berbasis Mobile } \\
\text { dengan telerbih dahulu } \\
\text { menekan tombol icon } \\
\text { aplikasi. }\end{array}$ & POLINDRA & $\begin{array}{l}\text { Jika sudah menekan icon aplikasi } \\
\text { virtual reality ini maka } \\
\text { selanjutnya akan masuk pada } \\
\text { tampilan menu utama. }\end{array}$ & \begin{tabular}{|c|} 
Main Menu \\
Mulai vR \\
Cara Paka VR \\
Tentang VR \\
\end{tabular} & $\begin{array}{l}\text { Sesuai yang } \\
\text { diharapkan. }\end{array}$ \\
\hline 2 & $\begin{array}{l}\text { Memilih menu mulai VR } \\
\text { untuk memulai berinteraksi } \\
\text { dengan duni 3D. }\end{array}$ & Mulai VR & $\begin{array}{l}\text { Jika sudah menekan tombol menu } \\
\text { mulai VR maka selanjutnya akan } \\
\text { menampilkan pilihan menu untuk } \\
\text { memilih gedung. }\end{array}$ & 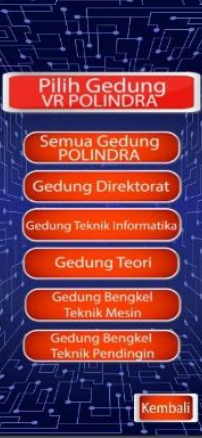 & $\begin{array}{l}\text { Sesuai yang } \\
\text { diharapkan. }\end{array}$ \\
\hline
\end{tabular}

\section{SIMPULAN DAN SARAN}

Kesimpulan yang didapatkan dari penelitian ini adalah :

1. Aplikasi 3D Virtual Reality Sebagai Media Pengenalan Kampus Politeknik Negeri Indramayu Berbasis Mobile bisa memberikan pengenalan kampus secara modern dan bisa membantu pengguna untuk mengetahui informasi tentang kampus.

2. Aplikasi 3D Virtual Reality Sebagai Media Pengenalan Kampus Politeknik Negeri Indramayu Berbasis Mobile adalah aplikasi untuk mengenalkan kampus dengan teknologi modern yaitu teknologi Virtual Reality agar pengguna bisa berinteraksi langsung dengan dunia 3D virtual reality dan mengutamakan user friendly bagi pengguna .

3. Aplikasi 3D Virtual Reality Sebagai Media Pengenalan Kampus Politeknik Negeri Indramayu Berbasis Mobile memiliki tampilan responsive dan bisa dijalankan di Smatrphone yang sudah mendukung sensor Accelerometer. sensor gyroscope, dan bersistem operasi Android dan pengguna harus menggunakan kacamata Google Cardboard atau VRBox.

Aplikasi virtual reality ini masih perlu dilakukan pengembangan dan penyempurnaan lebih lanjut. Berdasarkan kesimpulan diatas, maka saran yang dapat dikemukakan agar kedepannya lebih baik dan bisa disempurnakan adalah sebagai berikut:

1. Perlu ditambahkan detail objek yang digunakan pada virtual reality untuk memberikan kesan realistik yang lebih baik.

2. Menambahkan objek 3D lainnya yang terdapat pada kampus Politeknik Negeri Indramayu seperti gedunggedung yang belum dibuat dalam aplikasi. 
Jurnal Informatika dan Komputer (JIKO) - Vol. 2, No. 2, September 2017

\section{REFERENSI}

[1] Abidin, Riswan. 2016. Pengertian Virtual Reality. https://teknojurnal.com. Diakses pada tanggal 19 Maret 2017.

[2] Andika, Dwiky. 2015. Pengertian Virtual Reality. https://www.it-jurnal.com. Diakses pada tanggal 18 Mei 2017.

[3] Rohuda, Achmadyusuf. 2016. Apa itu VR Google CardBoard. http://rohudayusuf.blogspot.co.id. Diakses pada tanggal 25 Mei 2017.

[4] W. Goldstone. 2011. Unity 3.x Game Development Essentials - Game development with C\# and javascript. Mumbai: Packt Publishing Ltd.

[5] Hendratman, Hendi. 2015. The Magic of Blender 3D Modelling. Bandung : Informatika. 